\title{
O labirinto das memórias da antiga Igreja de Santo Alexandre: símbolos integrados e con- trastes da dinâmica do patrimônio sacro em Belém do Pará
}

\author{
The old church of Saint Alexandre's labyrinth of memories: integrated \\ symbols and contrasts of the dynamics of the sacred heritage in Belém, \\ Pará
}

Wagner Ferreira da Costa* Cybelle Salvador Miranda**

*Arquiteto e Urbanista formado pela Universidade Federal do Pará (UFPA). Mestre em Arquitetura e Urbanismo pelo Programa de Pós-Graduação em Arquitetura e Urbanismo (PPGAU/UFPA), enfoque em linguagem e simbologia arquitetônica sacra. Membro do grupo de pesquisa Arquitetura, Memória e Etnografia do Laboratório de Memória e Patrimônio Cultural (UFPA).
${ }^{* *}$ Arquiteta e Urbanista, Doutora em Antropologia pela Universidade Federal do Pará (UFPA). Professora da Faculdade de Arquitetura e Urbanismo e do Programa de PósGraduação em Arquitetura e Urbanismo (UFPA), coordena o Laboratório de Memória e Patrimônio Cultural (LAME MO), na Universidade Federa do Pará e lidera o grupo de pesquisa Arquitetura, Memória e Etnografia.

\section{Resumo}

$\mathrm{Na}$ arquitetura sacra cristã, o edifício em si e seus símbolos integrados (altares, púlpitos, mobiliário) constituem a materialização da cultura respeitante ao conjunto de crenças e tradições espirituais que fazem sentido à uma determinada comunidade. Tomando como objeto de análise a antiga Igreja de Santo Alexandre em Belém do Pará, visamos olhar este edifício e seus respectivos bens simbólicos como repositórios e/ou labirintos, nos quais a memória individual de seus frequentadores se ancora, seja pelo fator estético, histórico ou pelo afetivo. Ao longo do tempo, estas referências podem se perder, em razão das novas demandas sociais em que os edifícios históricos passam por processos de refuncionalização, visando substituir sua função de culto pela função museográfica. O caso da antiga Igreja de Santo Alexandre, em Belém Pará, torna-se emblemático para pensar as consequências das ações em que a patrimonizalização sobrepõe-se à patrimonialidade revelam, para a configuração de uma memória coletiva dos habitantes da cidade.

Palavras-chave: Patrimônio sacro. Memória Afetiva. Santo Alexandre.

\section{Abstract}

Christian sacred architecture, the building itself and its integrated symbols (altars, pulpits, furniture) are a materialization of culture into the set of spiritual beliefs and traditions that make sense for a particular community. Taking as an object of analysis the church of Santo Alexandre in Belém, Pará, we look at this building and its symbolic goods as repositories and/or labyrinths, in which an individual memory of its regulars is anchored, either by aesthetic, historical or affective reasons. Throughout time, these references may be lost, due to the priority of the largest social basis which demands actions of refuncionalization, such as the museal function of the sacred environments. The case of the former Church of Santo Alexandre, in Belém Pará, becomes an emblematic case in order to analyze the consequences of actions which overlap patrimonialization to the heritage values to the collective memory of the citizens.

Keywords: Sacred Heritage. Affective Memory. Saint Alexandre. 


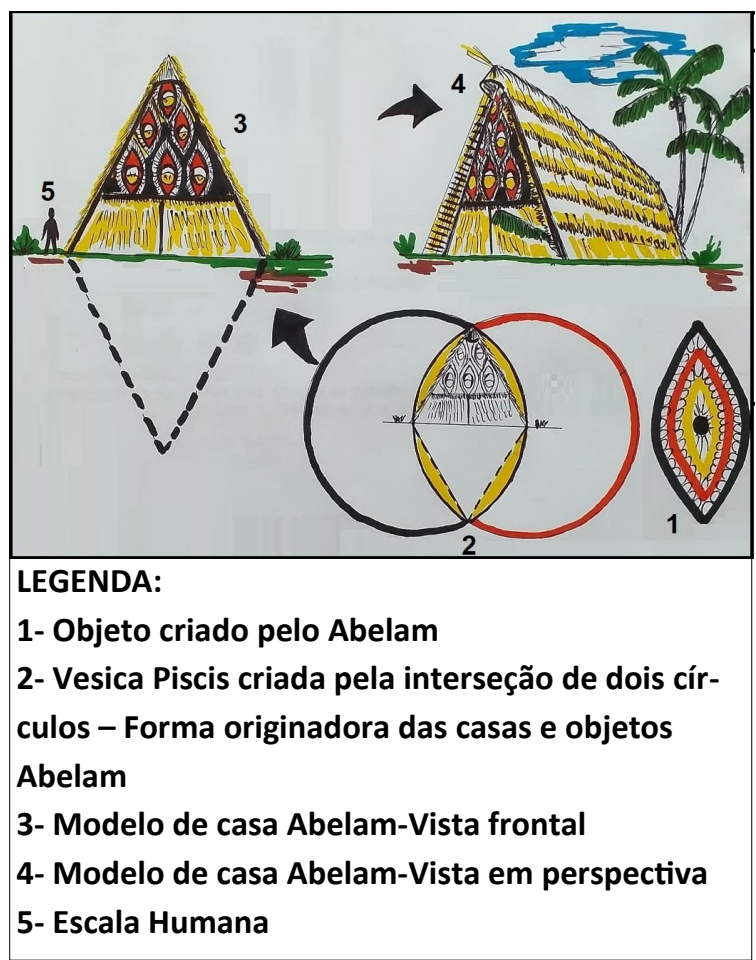

Figura 1. Casa característica dos povos Abelam em tons de vermelho, amarelo e preto. Fonte: Desenho do autor, 2019

\section{Arquitetura como materialização da cultura}

\section{$E$} tância da cultura para os diferentes povos. Aborda a cultura como o conjunto de manifestações dos costumes e crenças espirituais que diferenciam os grupos sociais entre si, evidenciando suas particularidades, expressas sob as formas imaterial e material. O primeiro aspecto diz respeito às crenças, hábitos e costumes, dentre outros, em suma, a forma com a qual o homem e/ ou seu coletivo particular (povo, etnia, grupo social) concebe o universo em que vive, enquanto o segundo aspecto se traduz na materialidade do que é produzido, a fim de suprir suas necessidades primárias, como no caso das construções arquitetônicas, servindo como abrigo. Desta forma, fica evidente que a arquitetura é uma materialização da cultura, originada pelas ideias, mitos e símbolos, pertencentes aos diversos grupamentos humanos.

Arquitetura é um símbolo cultural que, longe de apenas compor um mero cenário, permite a experimentação mais acurada das tradições cotidianas e espirituais às quais pertence. Forge (1967 apud-
GEERTZ, 2013, p. 151) dá-nos o exemplo dos Abelam e de sua relação com a forma simbólica dos círculos compostos em formas ovais e pontiagudas nas cores vermelha, amarela, branca e negra, que, em sua cultura, tem o mesmo nome de um ventre feminino, representando este poder através de seus objetos e formas arquitetônicas (Fig. 1).

A arquitetura não é apenas um monumento, conforme Le Goff (2003, p. 536), mas um documento histórico no qual podemos nos mover em duas direções: fisicamente, no interior de suas estruturas, e, memorialmente, quando perscrutamos o labirinto imagético de nossas lembranças. Os edifícios funcionam como registros dos acontecimentos, dos mais triviais aos de maior ênfase, são, portanto, repositórios da memória espacial construída coletivamente como visto na abordagem de Aleida Assmann (2003).

Através da concepção de Rasmussen (1998, p.23) podemos entender que as formas arquitetônicas são muito mais do que apenas materialidade, pois, enquanto símbolos, são influenciadoras de experi- 


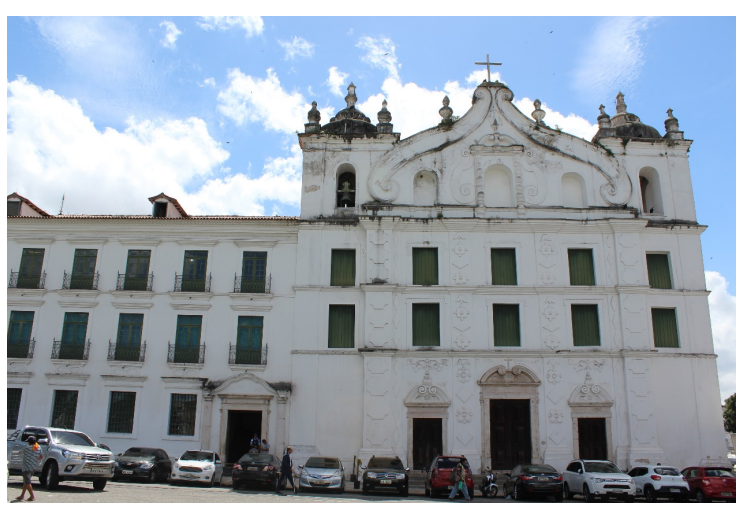

Figura 2. Fachada da Antiga Igreja de Santo Alexandre. Fonte: Vithória Silva, 2019 ências evocativas, trazendo à tona sentimentos advindos das memórias dos indivíduos que presenciaram a realidade destes espaços participando de suas atividades. A arquitetura é, desta maneira, uma transmissora dos valores sociais trazendo um sentido de comunidade:

[...] O homem está menos solitário quando sente ser parte de um movimento geral. As pessoas tentam assemelhar-se o mais possível [...] o objetivo da arquitetura é criar conjuntos integrados [...] (RASMUSSEN, 1998, p.23).

Tal excerto ganha uma base coerente em Geertz (2013) para quem as formas de representação artística do Quattrocento, quanto às diversas artes e produções humanas, estavam interligadas e convergiam ao ideal de religiosidade cristã. A transliteração deste aspecto na arquitetura deu-se na representação dos templos religiosos, por sua riqueza de ornatos simbólicos, onde o espaço e seus demais caracteres assumem função ritualística, como estruturas comunicantes de hierarquia, valores morais e religiosos, conforme for a disposição e orientação destes bens dentro de cada espaço, compondo as chamadas "estruturas de arranjo" de Baudrillard (1988).

No cenário local de Belém do Pará, encontramos na antiga Igreja de Santo Alexandre, um exemplar ao qual nos cabe analisar vendo-a como um símbolo e um labirinto das memórias, as quais foram perpetuadas ou se perderam desde o período em que a edificação estava fechada até sua reabertura após a restauração, em 1998, frente à dinâmica patrimonial.

\section{Antiga Igreja de Santo Alexandre: arquitetura, bens integrados}

Um dos edifícios sacros mais significativos no panorama visual da cidade de Belém do Pará é a antiga Igreja de Santo Alexandre (Fig.2), que integra atualmente o Museu de Arte Sacra, vista como um símbolo memorial e afetivo eleito pelo povo belemense como um dos edifícios cuja concretude encerra a cultura local, sendo, portanto, um "bem de herança", aquilo que merece ser preservado e transmitido às futuras gerações, constituindo o conceito ao que chamamos de patrimônio, valendo-nos da perspectiva de Poulot (2009).

Neste sentido, a transmissibilidade material e sensível do edifício de Santo Alexandre também corresponde ao conceito de tradição elaborado no pensamento de Mateus (2013), por dizer respeito ao aspecto particular com que nossas crenças, costumes e valores religiosos ou rituais de interação social se perpetuam e/ou são reinventados no decorrer do tempo.

É importante ressaltar nossa escolha em nos referir à edificação em questão com o predicado de "antiga igreja", haja vista que o ambiente, na atualidade, não exerce mais a função religiosa de templo, salvo 
excepcionais, como veremos adiante, servindo em função primária ao caráter museográfico. Na tentativa de entender como ocorreu esta transformação, da função sacra ao uso profano, apresentamos as diferentes etapas do edifício, desde sua construção às respectivas reformas do espaço até sua reintegração ao uso social, para que assim possamos entender como as memórias dos personagens que frequentaram o edifício enquanto igreja se perderam ou se perpetuaram após as reformas.

De acordo com o a publicação da SECULT- PARÁ Feliz Lusitânia/ Museu de Arte Sacra (2005), a antiga Igreja de Santo Alexandre foi construída pelos jesuítas no século XVII em Belém, através dos padres João de Souto Maior e Gaspar Fragoso, enviados por seu superior, padre Antônio Vieira, sofrendo reformas a partir do século XVIII, tendo o Barroco como estilo predominante, concordando com as referências de Bazin (1956).

A construção da igreja passou por três etapas principais até sua inauguração em 1719 , no século XVIII. A primeira liderada pelo padre João de Souto maior, em 1653, sendo uma simples construção de taipa e folhas de palmeira, enquanto que a segunda foi projetada pelo arquiteto Cristóvão Domingos e inaugurada em 3 de dezembro de 1668, dedicada à São Francisco Xavier (Santo que não tinha grande identificação por parte da população), enquanto que o colégio, que fora construído anexado ao templo, recebeu o nome de Santo Alexandre.
A antiga Igreja passou então a ter o mesmo nome do colégio, ao que se acredita, pela devoção que se tinha a este Santo, cujas relíquias foram dadas aos jesuítas pelo Papa Urbano VII, trazidas com a ordem à Belém. Serafim Leite, mencionado na obra da SECULT/PA, em sua "História da Companhia de Jesus no Brasil" (1943), chega ainda a mencionar o relicário encontrado no altar colateral da esquerda, demonstrando o sagrado inerente ao túmulo dourado do Santo.

Quanto à terceira etapa não temos a data exata do começo de sua execução bem como também da inauguração do espaço. Embora sua data de conclusão tenha sido assinalada entre 1715 e 1720, após ter suas obras paradas em 1714 por falta de recursos e retomada na gestão de Manoel de Brito, o mais provável é que tenha sido inaugurada em dezembro de 1718 ou março de 1719, conforme Leite (1943) aponta.

Quanto à forma, o antigo templo deve muito à igreja de Gesú em Roma, realizada por Vignola e Della Porta em 1568, pois foi de vital importância no sentido de inaugurar uma nova forma de disposição interna das edificações sacras, possuindo estas agora a inovação de uma nave única, o que conferia a elas o nome de igrejas-salão, conforme Bazin (1956): 


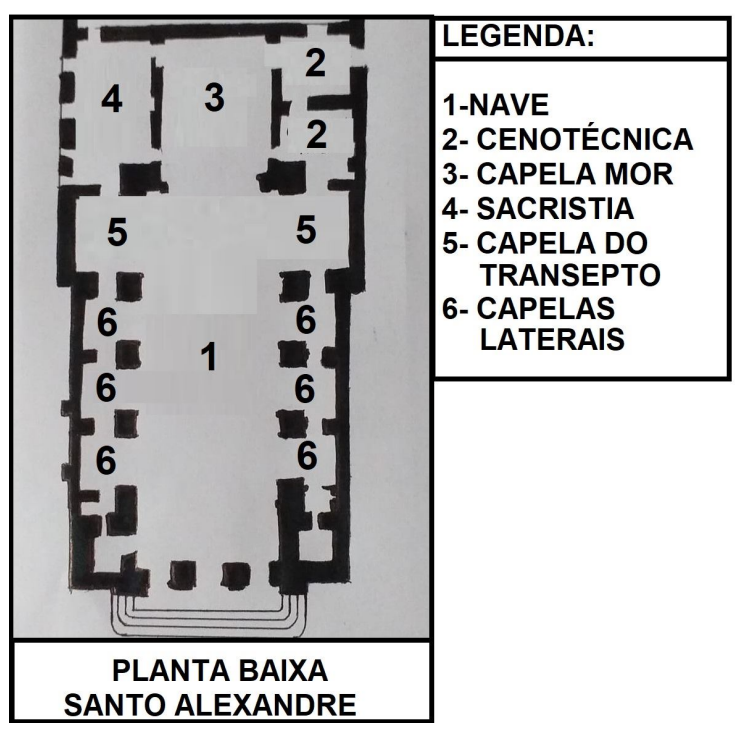

Figura 3. Planta-baixa da antiga igreja de Santo Alexandre. Fonte: Desenho do autor, 2019
[...] a característica desta é a combinação da nave única com a cúpula, e a redução da saliência do transepto, de forma a manter a planta baixa retangular, e só a abside sai desses limites. A ideia de reduzir o transepto poderia ter vindo da Espanha; efetivamente, com frequência ela se combina com a nave única, em especial nos templos da época dos reis católicos [...] Se, na planta baixa, o Gesú tende a ficar igreja inscrita em um retângulo, o corte horizontal, sobre as capelas, forma uma cruz latina. O Gesú, devido ao transepto ser da mesma altura da nave, permanece um templo de planta articulada, cujas naves côncavas servem de base para a cúpula; as capelas laterais profundas se intercomunicam e forma ainda uma espécie de naves laterais que, em elevação, se distinguem das naves altas nitidamente independentes [...] (BAZIN 1956, p.82).

A influência da igreja do Gesú em Santo Alexandre pode ser entendida por meio da análise de Jussara e Jorge Derenji no livro "Igrejas, Palácios e Palacetes de Belém" (2009), obra realizada em parceria com o IPHAN- PA, na qual explicitam a distribuição da planta baixa de Santo Alexandre:

[...] A planta da nave tem a forma de cruz latina com capelas comunicantes, três a cada lado, definidas por arcos redondos que se apoiam em pilastras. Sobre os arcos abrem-se as tribunas, estas com balaústres de madeira. Os retábulos seguem o estilo $D$. João $V$, sendo que os três à esquerda são originais, e os outros três, cópias em argamassa (DERENJI, Jussara; DERENJI Jorge. 2009. p. 117, 118) (Fig. 3).
Neste ponto devemos ressaltar a importância dos bens integrados para a edificação na construção de sua cenografia sacra, enquanto Igreja. Conforme ressalta o IPHAN em publicação eletrônica, os bens integrados constituem aqueles elementos que são acoplados ao corpo da edificação estrutural, tais como altares, capelas laterais, púlpitos, portas dentre tantos outros, cuja retirada ou modificação caracteriza a perda da referência e a dessacralização do espaço.

O homem é por excelência um animal simbólico, conforme Ernst Cassirer (1985) pontuou. É através do símbolo que os indivíduos condicionam sua visão de conceber o mundo traduzindo este saber em formas materiais correspondentes aos conceitos que querem abordar. No antigo templo de Santo Alexandre, o teor simbólico é percebido em escala macro por suas formas externas, enquanto que numa perspectiva micro dá-se no interior do espaço, nos símbolos encontrados na capela mor e nos púlpitos; estes estão recheados de figuras angelicais e símbolos femininos, como conchas, espeIhos, dentre outros, que trazem à tona a devoção mariana no espaço na medida em que desvelam a riqueza do barroco através de suas formas, como já pontuado por Derenji \& Derenji (2009).

Devemos ressaltar que, para além do valor estético histórico do edifício, evidenciamos a relevância sentimental que o mesmo representava para aqueles que vivenciaram as atividades deste espaço na 
1. GONÇALVES, José Reginaldo Santos. Os limites do patrimônio In: LIMA FILHO, Manuel Ferreira, ECKERT, Cornelia \& BELTRÃO, Jane (orgs.). Antropologia e patrimônio cultural: diálogos e desafios contemporâneos. Blumenau. ABA, Nova Letra, 2007. p. 242.

2. Agradecemos às Arquitetas doutorandas Catarine Saunier e Izabel Nascimento pela disponibilidade em encaminhar os contatos locais. época em que vigorava sua função de templo religioso, o que corresponde ao conceito de valor afetivo enfatizado por Cybelle Miranda (2012, p. 127). Outro paralelo pode ser traçado pelo conceito de ressonância ressaltado por Gimblett (1991 apud GONÇALVES, 2007, p. 242) ${ }^{1}$, que, por sua vez, trata de atingir um universo mais amplo quanto ao edifício, que traz à tona no expectador forças culturais complexas e dinâmicas em relação ao bem patrimonial, que é o templo, das quais este emergiu e das quais ele é, para àquele (expectador), o representante.

A dificuldade pertinente a validar a relação afetiva e memorial da antiga Igreja de Santo Alexandre está justamente no fato de encontrar os poucos habitantes do Bairro da Cidade Velha que ainda frequentaram este espaço na sua condição de templo, tornando estes personagens uma resistência viva memorial dos acontecimentos que se desenvolveram no ambiente sacro.

Perscrutamos o bairro em busca destes habitantes com investidas persistentes, cuja empreitada começou por volta do dia 26 de maio de 2019, Domingo, auxiliados por duas doutorandas do Programa de Pós-graduação em Arquitetura e Urbanismo². Catarine, a guia principal por ser moradora da Cidade Velha há cerca de 5 anos, nos apresentou a diversos vizinhos a fim de sondar aqueles que pudessem nos fornecer relatos acerca da antiga igreja.
Após tentativas infrutíferas com uma dezena de moradores, chegamos a Dona Rita, que cuida das atividades da Igreja de São João Batista, ou São Joãozinho, como é apelidada carinhosamente pelos fiéis. Em uma conversa simples ela nos informou que, embora não tenha frequentado Santo Alexandre, talvez alguns poucos fiéis da Igreja da Sé poderiam ter relatos interessantes, e desta maneira fomos convidados a participar da Missa de Segunda Feira às 19 horas, que é costumeiramente destinada à cura, na qual grande número dos participantes é composta por senhores e senhoras mais vividos, e, neste caso, Dona Rita faria o papel de intermediária.

Na segunda Feira, dia 27 de maio, chegamos meia hora mais cedo do que o estabelecido por Dona Rita, 18:30 horas, a fim de encontrar nossos informantes. Examinando o espaço e vislumbrando possíveis candidatos à pesquisa, abordamos alguns senhores de idade na tentativa de estabelecer um primeiro contato e desmistificar nossas intenções para com eles, afinal novos participantes no ambiente causam impacto visual e presencial, podendo gerar certa curiosidade, e, neste ponto, enquanto pesquisadores lançamos uma estratégia amistosa como forma de nos aproximar de nosso intento.

Passados os formalismos e atenuadas as desconfianças a nosso respeito, fomos parcialmente acei- 
3. Ser aceito na perspectiva de Geertz, significa que o pesquisador conseguiu ser visto como um membro do nicho cultural ao qual se propôs a vivenciar. tos $^{3}$, como personagens do ambiente, afinal, também utilizamos o pretexto de participar da Missa a nosso favor, e para estreitar a inteireza das relações mencionamos o nome de Dona Rita aos membros da assembleia, o que nos garantiu certo grau de confiabilidade a ponto de relatarmos nossas verdadeiras intenções quanto ao espaço.

Através dos fiéis soubemos que Dona Rita iria se atrasar devido a outro chamado de urgência que recebera, e, desta feita, estávamos por conta própria, contudo o instinto de ação enquanto observadores ativos, pareado à intuição nos permitiu chegar além das expectativas para o dia. Neste curto espaço de tempo, conversamos com mais de 7 pessoas, dentre elas fiéis e funcionários da edificação, até que pudéssemos encontrar Dona Nagibe Silva, 70 anos, moradora das imediações, que aceitou nos conceder entrevista sobre Santo Alexandre, realizada na manhã do dia 24 de junho de 2019.

Após uma conversa preliminar, perguntamos se ela chegou a participar de celebrações na antiga Igreja de Santo Alexandre e se tinha uma relação de proximidade com o espaço, ela nos informou suas vivências dentro da edificação de quando ainda era criança, afirmando que não participou ativamente das esporádicas celebrações do templo, mas apenas de visitações feitas com seus familiares ou quando as crianças que se preparavam para a Primeira Comunhão, que faziam parte da "cruzadinha", eram guiadas por sua professora de catequese:
[...] Participar da Santo Alexandre, não. Sempre participei da Catedral, porque naquela época a Santo Alexandre, no meu tempo, ela era a casa que o Bispo vivia, então tinha a Arquidiocese lá [...] então as freiras moravam ali, as freiras cuidavam e a Santo Alexandre só abria assim, nas horas das missas, pra algumas coisas importantes [...] de 1958 por aí que eu já "tava" na cruzadinha fazendo catequese pra Primeira Comunhão. Não me lembro assim de ir pra lá, ia visitar quando abria pra gente ver, pra gente fazer parte, depois ela passou uns vinte anos na reforma, ninguém entrava, agora que já faz visita, semana santa, ela abre, já tem alguns eventos que fazem lá [...] quando tinha alguma coisa lá na Santo Alexandre, às vezes nós íamos também pra lá, mas nós íamos acompanhados ou de parentes ou da professora da catequese [...] e ela explicava, ela mostrava, quer dizer, como a gente era uma préadolescente nessa fase, então ela orientava pra gente não tocar em nada [...] (D. Nagibe, 24/06/2019).

Pela análise do depoimento, pudemos observar que inexiste uma relação direta estabelecida no espaço por parte da fiel, uma vez que, devido a igreja ter permanecido sem atividade desde os anos 60 do século passado, só pessoas mais idosas poderiam ter memória de tê-la frequentado. Além disso, como o bairro encontrava-se dividido em freguesias religiosas, de modo que estas se situavam em torno da Igreja de São João, da Igreja do Carmo e da Catedral, apenas um segmento dos moradores do bairro dirigia-se a Igreja dos jesuítas. Contudo a visibilidade da carga memorial que o edifício encerra em si mesmo e o laço afetivo estabelecido pelos fiéis para 


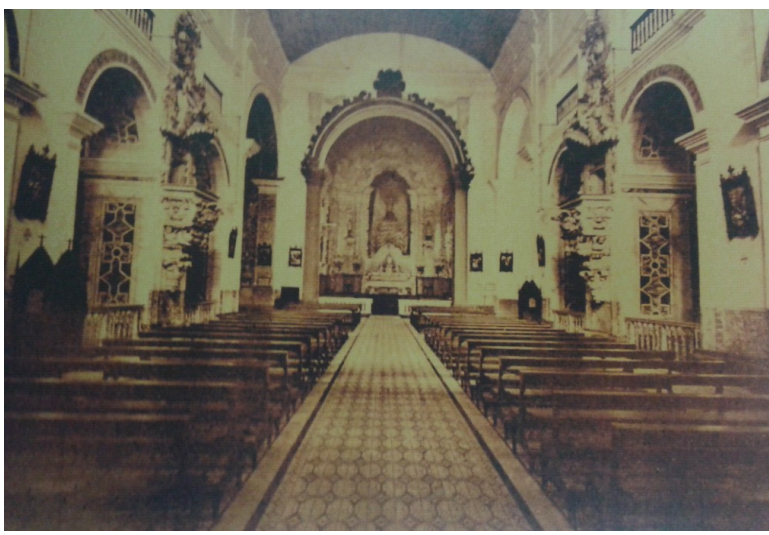

Figura 4. Interior da Igreja de Santo Alexandre por volta dos anos 1940, então com o piso em ladrilho hidráulico decorado. Fonte: Feliz Lusitânia/Museu de Arte Sacra, SECULT, 2005 Fonte: 81 . com este não passam desapercebidos, como bem sintetizado no depoimento do Sr. Aprígio, morador do bairro da Cidade Velha, à Miranda (2006, p. 161), quando perguntado sobre a antiga Igreja e o atual Museu de Arte Sacra, responde:

Estes relatos sinalizam a importância da antiga Igreja de Santo Alexandre e de seu conjunto de símbolos integrados como um repositório de memórias que aparentemente se perderam na medida em que o nexo estabelecido entre a disposição ambiental interna do espaço, a materialidade dos símbolos externos e internos e o laço afetivo criado entre participantes e edificação, como um todo, foram afrouxados pelas posteriores mudanças ocorridas $\mathrm{e}$ também pelo gradual desaparecimento de personagens que contribuíssem no sentido de passar adiante suas vivências à respeito do templo.

Desta feita, as lembranças fazem deste antigo lugar um verdadeiro labirinto de memórias que, embora desorganizadas, persistem na mente de alguns poucos residentes perseverantes no bairro e de seu entorno, e que por vezes vêm à tona numa tentativa de "rememorar" as experiências de um lugar, imbuído de significado, que se perdera por conta das decisões tomadas na tentativa de manutenção do patrimônio em seu caráter puramente técnico.

\section{Indústria patrimonial e o contraste do patrimô- nio: da antiga Igreja de Santo Alexandre ao atual Museu de Arte Sacra}

Após a expulsão definitiva dos padres jesuítas, em razão da laicização do Estado determinada pelo governo da época, composto pelo Secretário de Estado de Portugal Sebastião José de Carvalho e Melo, futuro Marquês de Pombal, em 1760 a Igreja de Santo Alexandre (Fig. 4) ficou abandonada até passar por reformas no século XIX, tendo em 1861, na administração do Dr. Francisco da Silva Castro, no cargo de provedor da Misericórdia, seu processo de recuperação iniciado, conforme aponta a SECULT-PA (2005).

No ano de 1974, o professor Ronaldo Marques de Carvalho, enquanto docente da disciplina Arquitetura Brasileira no Curso de Arquitetura da Universidade Federal do Pará, guiou os discentes a uma visita às igrejas de Belém, localizadas nos bairros da $\mathrm{Ci}$ dade Velha e Campina. Nesta atividade, professor e alunos se depararam com o ambiente sem atividade, no qual o Instituto do Patrimônio Histórico e Artístico Nacional coordenava a restauração da imaginária sacra pertencente ao templo, realizada pelo técnico João Mercês, especializado neste ofício. As imagens situavam-se no piso da nave da igreja, tendo sido muito afetadas pelos insetos xilófagos, bem 


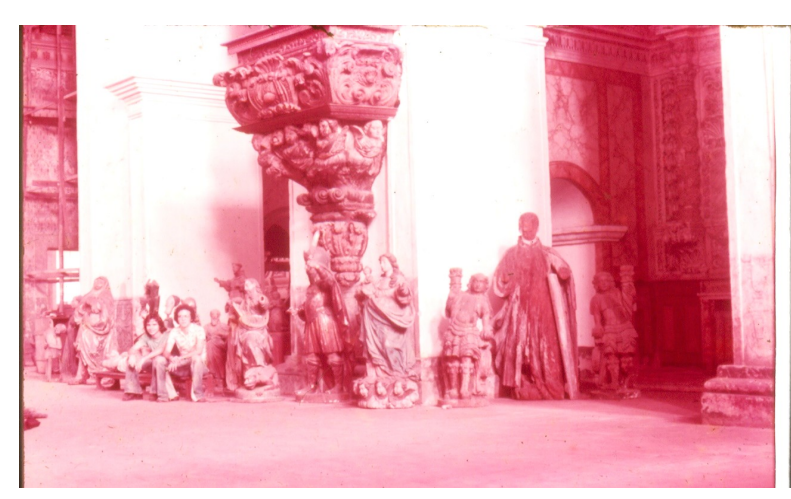

Figura 5: Imagens sacras dispersas na nave da Igreja, 1974 Fonte: Ronaldo Marques de Carvalho, 1974 como todos os bens integrados apresentavam estado de profundo abandono. Esta condição arrastou-se por mais duas décadas, sendo o local alvo de intervenções pontuais, como reparos na cobertura e salvaguarda dos bens integrados, quando, em finais dos anos 90 , foi objeto de uma intervenção de grande porte coordenada pela Secretaria de Cultura do Estado (Fig. 5).

A Equipe técnica do projeto destaca a Coordenação Geral de Projetos e Obras que ficou a Cargo do "Núcleo do Restauro da SECULT", sob a presidência de Paulo Chaves Fernandes" ${ }^{4}$.

No livro produzido com os resultados das pesquisas e intervenções que deram origem ao Museu de Arte Sacra, a apresentação "Ode para Dom Vicente e ao Arcanjo Gabriel", de autoria de Paulo Chaves, narra que os alunos do Curso de Arquitetura nos anos 60 (incluindo o próprio autor) lastimavam o destino da Igreja de S. Francisco Xavier, depois Santo Alexandre. Em frases poéticas, mostra que apesar do "título pomposo e da nobre função" estava "prestes a desmoronar sobre a luminosa cabeça de um abençoado Dom Vicente, a quem dedico, aliás, junto ao Arcanjo Gabriel, e sem os quais nada seria possível, a minha participação como coordenador de um trabalho que mobilizou centenas de pessoas, cujo principal atributo foi a paixão" (PARÁ, 2005. p. 5).
Como parte de um projeto maior, "O Projeto Feliz Lusitânia”, o qual teve início em 1997, na Gestão de Almir Gabriel, a restauração desse conjunto, que tem aproximadamente $25.000 \mathrm{~m}^{2}$, foi norteada por dois princípios básicos: a retirada de todos os acréscimos que agrediam e descaracterizavam os elementos mais originais de cada prédio; e a preservação - às vezes até mesmo valorizada - das alterações promovidas em diversas épocas e que foram consideradas como contributivas à artisticidade do conjunto. (PARÁ, 2005. p. 9 - grifo nosso). Segundo o texto, as intervenções basearam-se em pesquisas e prospecções, evitando o falseamento histórico através da reconstituição do perdido, bem como a refuncionalização visa dar usos mais compatíveis às demandas atuais da sociedade.

Quanto ao "Projeto de Restauração e adaptação de uso", o texto comenta sobre a recuperação e refuncionalização das edificações: o Museu de Arte Sacra tem acervo de mais de 380 peças, $1 / 4$ pertencente ao acervo jesuítico, encontravam-se guardadas nesta e em outras igrejas. 2/4 adquiridos dos herdeiros do colecionador Abelardo Santos e as restantes recebidas em doação. Destaca o rigoroso projeto luminotécnico e o esquema de segurança em consonância com padrões internacionais. O Museu contava, inicialmente, com os seguintes ambientes: cafeteria, Galeria de Arte, Auditório, oficina de restauração, loja de produtos culturais, Biblioteca especializada e igreja como sala de concertos. 


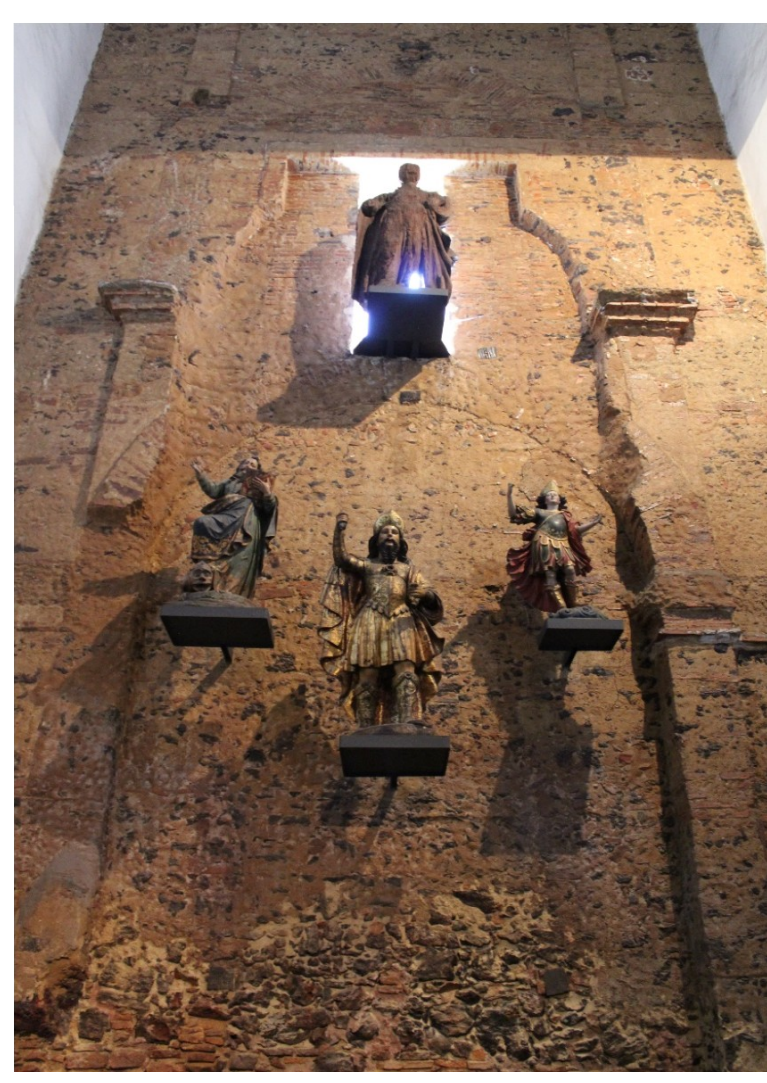

Figura 6. Parede do altar lateral do transepto, com alvenaria aparente. Foto: Vithória Silva, 2019.
No item pavimentação, o projeto optou por manter o piso em lajota de barro recente na nave da igreja, substituindo o piso da capela-mor em mármore preto e branco por tabuado de madeira de lei. Nas paredes, no local onde seria o altar esquerdo do transepto, como restaram apenas alguns vestígios sob o reboco que permitem identificar a existência da mesma, a solução encontrada foi a retirada do reboco, de modo que "Essa parede, então, foi deixada sem o revestimento para preservar a curiosidade das dúvidas que os vestígios de estruturas mais antigas sempre suscitam" (PARÁ, 2005. p. 123) (Fig. 6).

Do mesmo modo, o trecho em taipa localizado na sala esquerda à capela-mor, provavelmente da primeira igreja construída, foi revelado através de uma janela no reboco, que fica protegida por painel de vidro.

[...] Foram também restaurados os forros em madeira das galerias superiores, substituindo as peças danificadas por outras, obedecendo ao mesmo modelo, dimensão e técnica construtiva do original, não rompendo com a unidade estética que se queria recompor [...] (PARÁ, 2005. p. 124. grifo nosso).

Observa-se a unidade estética como um dos valores a serem recuperados com a intervenção, bem como a originalidade e artisticidade do conjunto, o que nos aponta para uma vertente de interpretação restauradora, que pode ser identificada a partir des- ses indícios, embora não seja explicitada no texto.

Quanto à restauração dos bens integrados, foi encontrada a continuidade do forro original do camarim, entalhado em madeira. Decidiu-se restaurar esse elemento, deixando-o visível pelo lado da igreja, mas separando o altar-mor da circulação do anexo por painéis de fibrocimento, mantendo-se a profundidade visual da capela e o uso do corredor, instalado no anexo posterior a igreja. A Via Sacra, já inexistente, foi substituída por conjunto transferido de uma igreja no interior do Pará. O pátio nos fundos do anexo posterior à Igreja foi denominado "Jardim do Tempo", nele sendo implantado um anfiteatro e depois da demolição dos anexos pode-se analisar os fundos das edificações da Rua Padre Champagnat.

Desenhos mostram o antes (1996) e o depois das intervenções (1998), bem como a documentação fotográfica da Restauração. A seguir, o artigo "Museu de Arte Sacra do Pará: um ensaio Museológico na Amazônia" de Maria Ignez Mantovani Franco destaca a disposição política que levou à criação do Museu de Arte Sacra como "um cenário cultural incomum" (PARÁ, 2005. p. 257), com a restauração do conjunto arquitetônico jesuítico e a árdua batalha para impedir a dispersão da Coleção Abelardo Santos de obras sacras. O projeto museológico, de caráter interdisciplinar, aproveitou o mapeamento da Coleção Abelardo Santos pelo IPHAN, empreendeu o conhecimento da história das ordens religiosas no 
Pará e o panorama da vida religiosa da população, sendo esta pesquisa realizada pelo Professor Geraldo Mártires Coelho, responsável desde os esboços cronológicos "até a elaboração dos densos e tão eloqüentes textos que compõem os painéis explicativos do circuito expositivo" (PARÁ, 2005. p. 258).

Cita a participação da Arquidiocese como solidária ao projeto, orientando as pesquisas em igrejas na busca por "obras representativas que já estivessem fora de culto e, portanto, passíveis de serem integradas ao Museu" (PARÁ, 2005. p. 258). Foram convidados dois especialistas: Myriam Ribeiro de Oliveira que fez a reanálise da imaginária e o pesquisador João Moreira Garcez Filho, que analisou a prataria. Segundo Maria Ignez, o conceito museológico norteador dividiu-se em três vetores: 1) mapeamento religioso de Belém; 2) Igreja de Santo Alexandre como objeto museal magno; 3 ) Iconografia dos Santos. Para garantir a continuidade do projeto, foram elaborados instrumentos jurídicos de consolidação museológica: Sistema Integrado de Museus do Pará, composição de instância colegiada consultiva para o Museu, organograma funcional do Museu, proposição de quadro técnico e administrativo e plano de gestão.

Quanto ao partido museológico e ao programa museográfico, a escolha dos suportes metálicos deveu-se à articulação com as soluções arquitetônicas da restauração do monumento. O projeto mu- seográfico foi elaborado por Gerardo Vilaseca com a execução da arquiteta Filomena Mata Longo. Elemento estrutural do discurso expositivo, a iluminação projetada por Jean François Hocquard imprimiu teatralidade ao circuito expositivo, criando "auras luminosas para as imagens do acervo" (PARÁ, 2005. p. 259). Quanto aos caminhos prospectivos, a autora aponta a constante interação com a população de Belém como fator fundamental para a manutenção do espaço.

Deste modo, o patrimônio cultural sacro edificado da antiga Igreja de Santo Alexandre passou não somente por modificações físicas, mas também ideológicas devido à sua antiga função, enquanto objeto de culto, ter sido substituída por uso cultural como parte do Museu de Arte Sacra do Pará, devido às escolhas realizadas na época, o que consequentemente tornou o espaço cenário propício para as forças do mercado da indústria patrimonial, que busca vender o bem como produto.

Nesta perspectiva, Gonçalves (2007, p. 243) relata que, antes, o mercado do patrimônio era visto como principal agente no que tange a dessacralização e perda de autenticidade dos bens, entretanto, hoje em dia ele se tornou "aliado" do patrimônio, tendo este uma dupla função na visão de Françoise Choay (2000), pois ao passo que tem a intenção de propiciar o acesso e experimentação de seu espaço a todos, talvez numa tentativa de mantê-lo, também o vende como produto a ser consumido, participando 


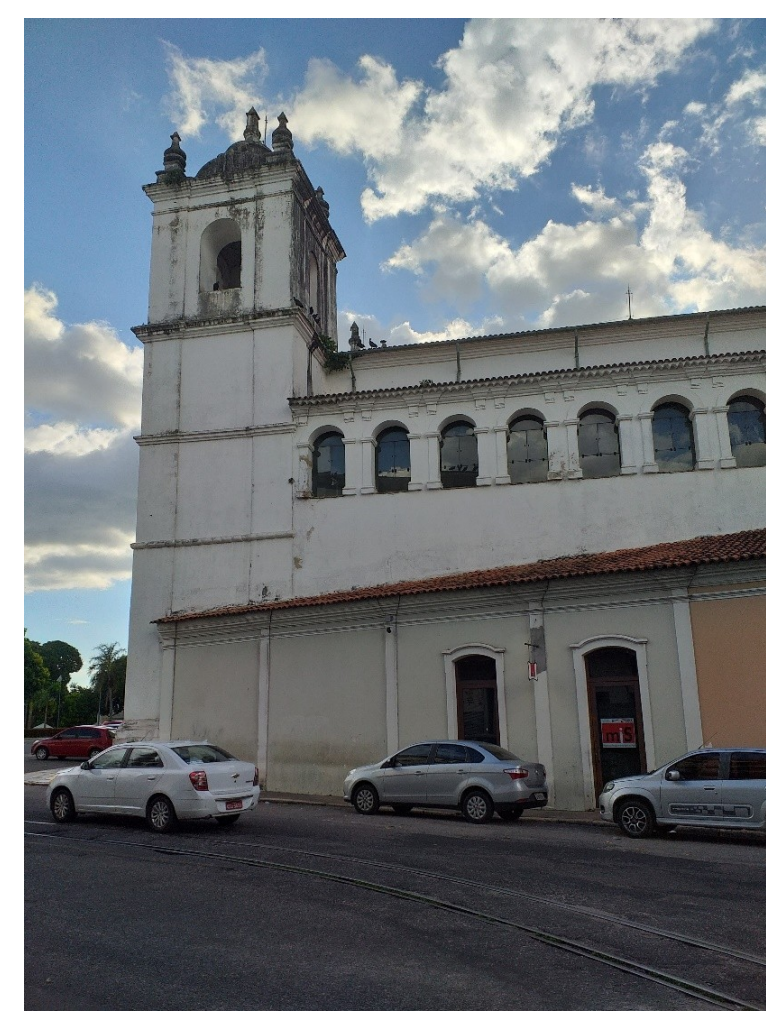

Figura 7. Torres de Santo Alexandre como ponto sinalizador. Fonte: Foto do autor, 2019.

\section{de uma lógica arbitrária de "valorização".}

Através da antiga Igreja de Santo Alexandre, notamos a profundidade do contraste representado na dinâmica patrimonial pelas modalidades da patrimonialidade e patrimonialização. A primeira como estratégia sensível atribuída ao valor do patrimônio, que reconhecido pela população, tenta salvaguardá-lo, como diz Poulot (2009), enquanto a patrimonialização participa das empreitadas econômicas do mercado da indústria patrimonial na era da cultura, onde tudo vira uma atração turística e onde as experiências vividas no espaço nada mais são que uma reprodução forjada de um lugar que não mais existe.

Externamente, a fachada da edificação sacra voltada para a cidade, com suas volutas unindo-se em direção aos céus culminando em uma cruz, bem como suas torres que a tornam um ponto de referência visual, como Peixoto salienta no capítulo "Imago Urbis" (1996, p. 258) ao tratar dos edifícios sacros, fazem com que ainda tenhamos a referência do espaço como um templo religioso (Fig. 7). Na pesquisa de Mateus Nunes (2018), a ênfase recai sobre as volutas 'toscas' da fachada da igreja jesuítica, atributo barroco numa igreja chã:

[...] Então, neste pensamento de complexidade, movimento e infinitude, especula-se que estas deformações não tenham sido aleatórias e imprevistas. É perceptível que algo transformador
- como um processo de mutação - acontecia nos trópicos, mas já que vários elementos arquitetônicos na igreja são executados de maneira usual às outras igrejas jesuíticas ao redor do mundo, em que não há deformações brutais - o termo "brutal" é de Lúcio Costa - que saltam aos olhos, as deformações nas "volutas" da Igreja de Santo Alexandre podem ser caracterizadas como incidente, ao invés de acidente [...] (NUNES, 2018. p. 38)

A permanência da percepção do edifício enquanto templo é assinalada no discurso de D. Nagibe, embora ela alerte que o espaço seja de acesso restrito à população após as reformas respectivas, comentando ainda sua visão após a transformação do bem em Museu de Arte Sacra, dando falta de algumas Imagens de Santos:

[...] Eu acredito que ela seja uma Igreja sim, mas não uma Igreja pro público fazer parte como a Catedral como "tá", como a Igrejinha de São João, é muito fechada, que eu não sei porquê que ela não ficou mais aberta, ficou fechada [...] Sim, eu entrei logo que foi inaugurado o Museu, a gente foi visitar, aí a gente viu que muitas Imagens ali não estavam mais, uns dizem que é porque "tavam" quebradas, não tinha como fazer reforma, e não sei pra onde foi, não posso dizer pra onde foi, nunca me informei [...] depois da reforma muitas estátuas não estão ali, não aparecem e ficou também o Museu onde foram algumas estátuas, que eu não sei se foram pra lá, passaram pra lá, mandaram fazer reforma, ficaram do jeito que está porque também o Patrimônio impede muita coisa, Patrimônio não tem dinheiro, mas ele pede, porque tem que conservar [...](D. Nagibe, 24/06/2019). 


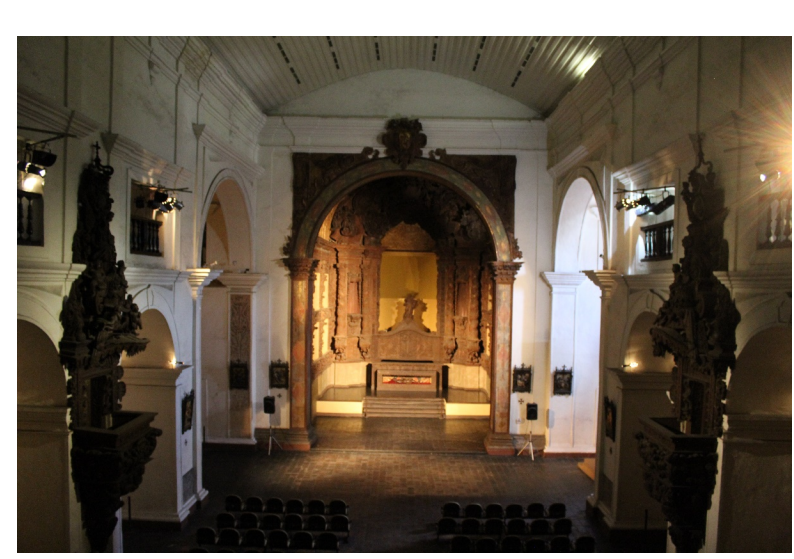

Figura 8. Interior da Igreja de Santo Alexandre, nave da Igreja com seus púlpitos e altar-mor iluminados. Fonte: Vithoria Silva, 2019.

usjt • arq.urb • número 27 | janeiro - abril de 2020
Internamente, por sua acústica, o ambiente foi transformado em sala de concertos, o que reforça a cenografia do espaço como pano de fundo. A disposição do mesmo e de seus bens simbólicos integrados, como altares (estes destituídos da Imagem dos Santos), púlpitos, lembram o aspecto da ritualística que ali uma vez se desenvolveu. Não raro ocorrem celebrações matrimoniais, dado o fator memorial do bem patrimonial como Igreja, que ressurge nestas ocasiões, como memórias mortas, no que podemos chamar de uma ressurreição simbólica convencional, pelo fato de o objeto não ser mais Igreja, senão parte do atual Museu de Arte Sacra, evidenciando com mais intensidade o contraste patrimonial existente (Fig. 8).

Um outro ponto que descaracterizou o bem como templo religioso foi a transferência da entrada principal do átrio da edificação para a sua lateral, como suscitou Miranda (2006), constituindo uma negação de seu aspecto eclesiástico e relegando-o ao uso comum, visto que é a porta central na fachada da antiga Igreja que assinala a diferenciação entre espaço exterior (comum) e a realidade interior (sacra), além de anunciar o início do caminho processional que leva ao altar mor. Assomado a isto, a fala de D. Nagibe traz à luz o possível aspecto estratégico desta transformação no sentido de proteção do bem:

[...] porque a porta principal, eu acho que eles não abrem, pois como ela não "tá" ao público, aberta, então se tu fores fazer visita, e pra não ter problema de desaparecer alguma coisa, então eles deixam pela porta lateral que tem os guardas municipais ali tomando conta e mais as pessoas responsáveis [...] pra proteger e também pra conservação, porque tem muita gente que vai olhar e vai mexer, deixa cair e quebra, $\mathrm{e}$ isso a gente vê aqui na Catedral que é aberto ao público e tem gente que entra pra mexer, tocar, cair, quebrar, e as vezes não tem jeito quando fazem isso porque são peças que você não tem como reformar [...](D. Nagibe, 24/06/2019).

É notável que há uma relação antagônica representada pelo estranhamento da população em reconhecer o edifício destituído de sua função sacra e a posterior e paulatina "aceitação" aparente de seu novo uso após as transformações, ou seja, a mesma relação dada entre a assimilação do passado (vestígios e restos) e a estranheza do antigo no presente definida por Miranda (2016, p. 408), que reconhece o patrimônio como uma dialética entre conservação e destruição, visto que arquitetura pode ser enxergada como um ente no qual as etapas se impregnam, juntam ou excluem, principalmente quanto às intervenções realizadas no mesmo. Para D. Nagibe, as formas gerais da antiga Igreja se mantêm, e quanto ao aspecto material geral do bem, as mudanças vieram num sentido de preservar o que já existia:

[...] Não olha, eu acho que assim, não teve tanta mudança, ela continua o mesmo estilo, o que mudou que eles fizeram o sino tocar, que não tinha, "tava" esbandalhado, que eu nem sei te dizer se ele ainda toca porque eu não escuto, não 
sei nem se ele ainda tá lá [...] Então algumas coisas que mudaram de quando a gente viu a reforma ela ficou bem melhor, limpinha, pintada, conservada, e todo mundo tem que conservar "né"? O patrimônio, a gente é dono cada um conserve o seu [...](D. Nagibe, 24/06/2019).

Embora as mudanças tenham contribuído, em certa medida, para a manutenção do edifício de Santo Alexandre, não é somente o fator material que está em jogo, mas as relações memoriais vivenciadas no espaço. Certamente, o período em que a Igreja ficou fechada contribuiu para a desestruturação e modificação das dinâmicas ritualísticas ali desenvolvidas, bem como trouxe uma cisão quanto ao fator afetivo do povo belemense e de suas memórias quanto ao templo. Bógea (2009, p. 3) menciona que os ambientes construídos pelos homens guardam "a memória das ideias, das práticas sociais e dos sistemas de representação dos indivíduos que ali convivem", mas alerta sobre a importância das escolhas feitas quanto aos bens que servem como repositórios da memória para manter a cultura viva:

[...] O processo de ativação da memória, implícito na ação de preservação do patrimônio cultu ral, corresponde a programar o esquecimento, a controlar seletivamente aquilo que se considera de fato relevante e que portanto interessa manter vivo como elemento depositário de valor cultural [...] Nesse sentido é fundamental a reflexão teórica já produzida e consolidada, como instrumento que formula os princípios gerais a serem elaborados nas circunstâncias específicas dos casos analisados [...] (BOGÉA, 2009, p. 4-5).
O discurso de Janescléia Machado, de 34 anos, turismóloga que trabalha no ramo de edifícios sacros, retrata bem a dessacralização do lugar enquanto templo religioso, no sentido de negação às escolhas feitas para a revitalização do bem:

[...] Totalmente, perdeu a essência de templo religioso, atualmente tem a função somente de museu e de visitação, mas o que dá vida pro templo são as celebrações, são as missas, é o fiel entrando, frequentando. É isso que dá vida! Se tu tiras as pessoas dali tu perdes a essência do lugar, fica uma casa vazia, e casa vazia não traz alegria, traz? Não traz! O que traz alegria é a convivência "né"? As pessoas celebrando, cantando, louvando, agradecendo, se emocionando, é isso [...] (Janescléia Machado, 15/03/2019).

Podemos depreender que a reintegração deste patrimônio à vida cotidiana deveria ter sido analisada e realizada com mais esclarecimento no que diz respeito a uma intervenção mais acurada e consciente, que não ferisse a essência e equilíbrio do espaço, mas enaltecesse os seus valores (RIBEIRO, 2013), sem que o templo tivesse sua função modificada para servir a outros interesses. Além disto, não houve uma participação popular no que tange as decisões engendradas no bem, como afirma D. Nagibe quando perguntada sobre o assunto:

[...] Não. Que eu me lembre assim não. Nunca ouvi minha mãe falar, nunca ouvi minhas tias falarem, que a minha mãe, minhas tias, todas faziam parte da Catedral, as cunhadas, que eram 
casadas com meus tios, irmãos delas, tanto da parte do meu pai como da parte da minha mãe[...](D. Nagibe, 24/06/2019).

Neste quesito, Miranda (2016, p. 418) aponta os aspectos simbólico-representativos para a população e não os de cunho estético-histórico à maneira que fazem os técnicos como solução viável para a promoção de uma reabilitação eficaz. Esta prática reflexiva poderia muito bem ser utilizada no processo de restauração da antiga Igreja de Santo Alexandre, uma vez que é a população, enquanto reconhecedora de seu patrimônio que deveria sinalizar o que pode ou não ser mantido e legado às futuras gerações. Salvaguardando o bem em sua essência material e simbólica, promovendo a patrimonialidade do bem frente à patrimonialização e investidas do mercado patrimonial que subjugam nossa herança material a uma condição de consumo, fortalecendo, desta maneira, a cultura local através de sua produção arquitetônica enquanto símbolo sacro e patrimonial.

\section{Considerações Finais}

Argan (1992) compactua ao falar das imagens e símbolos como dando consciência aos conceitos. Tratamos de sinalizar a antiga Igreja de Santo Alexandre como um símbolo de identidade, que através de sua expressão externa e realidade interna funciona como um receptáculo das memórias do povo belemense, constituindo sua forma física a materialização dos valores e crenças religiosas lo- cais, portanto, da cultura como apresentado em Silva (1994)

O período em que a antiga Igreja de Santo Alexandre ficou fechada, sua posterior restauração e reintegração à vida presente compondo parte do $\mathrm{Mu}$ seu de Arte Sacra de Belém, causou grande impacto no sentido memorial do edifício enquanto templo, tendo seu uso sacro reconfigurado à um uso trivial, neste espaço de tempo, faz-nos pensar a respeito da importância da prática reflexiva como caminho para proteção dos símbolos a que chamamos de patrimônio.

Atentar para a dinâmica patrimonial por via de suas duas modalidades explanadas em Poulot (2009), antagônicas e ao mesmo tempo complementares, a patrimonialidade, que busca a salvaguarda do bem em suas múltiplas dimensões, e a patrimonialização, que se beneficia do bem transformando-o em produto, tornaram o edifício de Santo Alexandre palco de disputas, onde a última modalidade parece ter sobressaído, devido às escolhas feitas na época em que a edificação estava em reparos.

De certo, o fator estético-histórico teve sua importância quanto ao restauro da edificação sacra de Santo Alexandre na medida em que viabilizou a manutenção da materialidade do bem, contudo, deveria ser o valor afetivo como sendo o responsável pela perpetuação da imagem do espaço enquanto lugar do sagrado nas diferentes memórias do povo 
belemense a fim de que estas se mantenham vivas, por mais que as atribuições do espaço atualmente sejam outras. Para tanto, a sugestão de valer-se de intervenções conscientes e criteriosas, pautadas em aspectos simbólico-representativos e não somente em fatores técnicos, deveriam ter sido a estratégia utilizada no restauro do edifício sacro em questão, pois a materialidade sugere vivência e memória.

\section{Referências}

ARGAN, Giulio Carlo. História da arte como história da cidade. São Paulo: Editora Martins Fontes, 1992.

ASSMANN, Aleida. A gramática da memória coletiva. In: Humboldt 86, Bonn, Goethe-Institut Inter Nationes, 2003. p. 2-4.

BAUDRILLARD, Jean. O Sistema dos Objetos. 5. Ed. São Paulo: Perspectiva, 1988.

BAZIN, Germain. A Arquitetura Religiosa Barroca no Brasil- Volume 1. Rio de Janeiro. Editora, Record, 1956.

BOGÉA, Marta; ALMEIDA, E. Esquecer para preservar. Arqtexto, UFRGS, v 15, 181- 209, 2009.

CASSIRER, Ernst. Linguagem e mito. $2^{\mathrm{a}}$ ed. São Paulo: Editora Perspectiva, 1985.

CHOAY, Françoise. A Alegoria do Patrimônio. Lisboa: Edições 70, 2000.

DERENJI, Jussara da Silveira. Igrejas, palácios e palacetes de Belém. Brasília, DF: Iphan / Programa Monumenta, 2009. (Roteiros do Patrimônio; 6)

GEERTZ, Clifford. Arte como sistema cultural In: $\mathbf{0}$ saber local - novos ensaios em Antropologia Interpretativa. Petrópolis: Vozes, 2013. 
GONÇALVES, José Reginaldo Santos. Os limites do patrimônio In: LIMA FILHO, Manuel Ferreira, ECKERT, Cornelia \& BELTRÃO, Jane (orgs.). Antropologia e patrimônio cultural: diálogos e desafios contemporâneos. Blumenau. ABA, Nova Letra, 2007.

\section{INSTITUTO DO PATRIMÔNIO HISTÓRICO E AR-}

TísTICO NACIOINAL (IPHAN). Disponível em: http://portal.iphan.gov.br/mg/pagina/detalhes/1299. Acesso em: 10 mai 2019.

LE GOFF, Jacques. Documento/monumento In: História e memória. 5. ed. Campinas, SP: UNICAMP, 2003.

MATEUS, João Mascarenhas. A questão da tradição. História da construção e preservação do patrimônio arquitetônico. PARC Pesquisa em Arquitetura e Construção. Campinas: UNICAMP, vol3 n4, abril 2013, p.27-32.

MIRANDA, Cybelle Salvador. Cidade Velha e Feliz Lusitânia: cenários do Patrimônio cultural em Belém. Tese (Doutorado em Ciências Sociais). Universidade Federal do Pará, Centro de Filosofia e Ciências Humanas, Belém, 2006.

MIRANDA, Cybelle Salvador. Lugares de memória: a profissionalização da cultura e do patrimônio em Belém-PA In: Arte e Cultura na Amazônia: os novos caminhos. $1^{\mathrm{a}}$ ed.Boa Vista: Editora da UFRR, 2012, v.1, p. 61-85

MIRANDA, Cybelle Salvador. Restauração como tradução: intervenções na Igreja de São João Batista em Belém (1994-1996). Revista CPC (USP), v.15, p.109 - 136, 2012.

MIRANDA, Cybelle Salvador. Ruínas, Duração e Patrimonialidade. Rua (UNICAMP), v.2, p.407 424, 2016.

NUNES, Mateus Carvalho. Transdobra: acidente barroco na Igreja Jesuítica de Santo Alexandre Ou Da possibilidade de haver um elemento confluente ao pensamento barroco em uma igreja não-barroca, 2018. Monografia (Graduação em Arquitetura e Urbanismo). Universidade Federal do Pará, Instituto de Tecnologia, Belém, 2018.

PARÁ. Secretaria Executiva de Cultura do Estado. Feliz Lusitânia/ Museu de Arte Sacra. Belém: SE-

\section{CULT, 2005.}

POULOT, Dominique. Uma história do patrimônio no Ocidente. São Paulo: Estação Liberdade, 2009. RAPOSO, Maria Tereza Resende. O Conceito de Imitação na Pintura Renascentista e Impressionista.

Metanoia Revista Eletrônica, São João del-Rei, $n$. 1, p. 43-50, 1998/1999. 
RASMUSSEN, Steen Eiler. Arquitetura Vivenciada. São Paulo: Martins Fontes, 1998.

RIBEIRO, Rosina Trevisan M. Técnicas construtivas tradicionais: preservação de um saber fazer In: RIBEIRO, Nelson Pôrto (org.). Subsídios para uma história da construção luso-brasileira. Rio de Janeiro: Pod Editora, 2013.

RUBIÓ, Ignasi de Solà-morales. Do contraste à analogia: novos desdobramentos do conceito de intervenção arquitetônica In: NESBITT, Kate (org). Uma nova agenda para a Arquitetura. São Paulo: Cosac Naify, 2008. Françoise. A alegoria do Patrimônio. Lisboa: Edições 70, 2000.

SILVA, Elvan. Matéria, Ideia e Forma: uma definição de Arquitetura. Porto Alegre: Ed. UFRGS, 1994. 